\title{
Vaccination Status and Factors for Non- Vaccination in Children at a Tertiary Care Hospital
}

\author{
Shiyam Sunder Tikmani ${ }^{2 *}$, Tufail Soomro' ${ }^{1 *}$, Sumera $\mathrm{Ali}^{2}$ \\ ${ }^{1}$ Department of Paediatrics, Ghulam Mohammad Mahar Medical College, Sukkur \\ ${ }^{2}$ Department of Community health Sciences, Aga Khan University, Karachi
}

\begin{abstract}
Received: June 25, 2016; Accepted: July 4, 2016; Published: July 15, 2016
*Corresponding authors: Tufail Soomro FCPS, Assistant Professor, Department of Paediatrics, Ghulam Mohammad Mahar Medical College, Sukkur, Tel: +92333-727-9661; E-mail: drtufailsoomro@hotmail.com

Shiyam Sunder Tikmani MSc, Instructor, research, Department of Community health Sciences, Aga Khan University Karachi, Tel: +92-348-648-96;E-mail: Shiyam.sunder@aku.edu
\end{abstract}

\begin{abstract}
Immunization is a very effective strategy to prevent against common infectious disease. The objectives of the study were to determine the immunization status and reasons for non-vaccination of children coming to Civil Hospital Sukkur. This cross-sectional study was conducted pediatric OPD at Civil Hospital Sukkur from January 1, 2013, to June 30, 2013. Parents of children under five years of age brought their child to Outpatient Department of Civil Hospital Sukkur for any illness were asked to participate in the study. Parents who gave informed consent were included in the study. Data were collected using a small questionnaire by the researcher himself. A total of 500 parents gave consent to participate in the study. The average age of children was $20.4 \pm 16.3$ months, 257 (51.4\%) were males and $243(48.6 \%)$ were females. Four hundred and four (80.4\%) children were fully vaccinated and $98(19.6 \%)$ were not vaccinated. Parents don't know about immunization, busy parents, illness of a child, fear of immunization and parents who are not considering immunization as important are independent factors of non-vaccination.
\end{abstract}

Keywords: Vaccination; Immunization; Factors; Children

\section{Abbreviations}

AHP: Accelerated Health Plan; BCG: Bacillus Calmette-Guérin; DPT: Diphtheria, Pertussis, Tetanus; EPI: Expanded Program of Immunization; KPK: Khyber Pakhtunkhwa; LB: Live Birth; NID: National Immunization Days; OPD: Out-Patient Department; OPV: Oral Polio Vaccine; PDHS: Pakistan Demographic \& Health Survey; WHO: World Health Organization

\section{Introduction}

In the $20^{\text {th }}$ century, immunization programs are one of the most effective health interventions and their success is connected to achieving and maintaining high vaccination coverage rate[1]. The morbidity and mortality due to vaccine preventable disease are still very high in many developing countries including Pakistan [2]
Fifteen percent of Pakistan population constitutes children under five years of age. These children contributed $50 \%$ of overall mortality compared to 8-10 in high-income countries [3]. The rate of mortality of children under five years of age is high in South Asian countries. According to the World Bank, the under-five mortality rate is quite high for Pakistan 81/1000 live births (LB) compared to India 48 and Bangladesh 38/1000 LB.[4] Communicable diseases are a major cause of under-five mortality. To develop preventive measure against communicable diseases, a pilot project of expanded program of immunization (EPI) had been launched in 1974. In 1985, this program was further augmented by accelerated health plan of government (AHP) which resulted in improving coverage from a low $5 \%$ to $70 \%$ in 1984.[5,6] in the last decade national immunization days (NIDs) and the mopping up campaigns (door to door vaccination in high-risk areas) have been introduced to provide maximum coverage $[7,8]$.

In developing countries, vaccinating children has the highest impact on health intervention that not only reduces hospitalization but also decreases the treatment cost through prevention $[9,10]$

The vaccine coverage varies according to the province of Pakistan. According to recent Pakistan Demographic and health survey (PDHS) 2012-2013 [11], the coverage of BCG was 91.6\% in Punjab, 78.5\% in Sindh, 79.7\% in Khyber Pakhtunkhwa (KPK), $48.9 \%$ in Balochistan, Islamabad $96.5 \%$ and Gilgit Baltistan 78.6\%; coverage of 3 doses of DPT was 76.3\% in Punjab, 38.6\% in Sindh, 69.6\% in KPK, 27.2\% in Balochistan, in Islamabad 91.2\% and Gilgit Baltistan 55.3\%; coverage of polio dose III was $92.4 \%$ in Punjab, 77.5\% in Sindh, 75.7\% in KPK, 60.6\% in Balochistan, Islamabad $85.6 \%$ and Gilgit Baltistan $75.2 \%$ and coverage of measles was $70 \%$ in Punjab, $44.6 \%$ in Sindh, $57.8 \%$ in KPK, $37.3 \%$ in Balochistan, Islamabad 85.2\% and Gilgit Baltistan 51\%

According to PDHS 2012-13, full vaccination coverage in Pakistan has been gradually improving over the past two decades, 
with an increase from $35 \%$ in $1990-91$ to $54 \%$ in $2012-13$ [11]. A hospital based study showed that $58 \%$ of children at risk remain unimmunized due to lack of implementation and monitoring awareness.[12] In Karachi, only 25\% of general practitioners had adequate knowledge about pre-exposure and only $13 \%$ both pre and post-exposure tetanus immunization.(7,13) In KPK, 65\% children were immunized fully, among whom only half could be verified for immunization.(14) A study in Karachi showed a low level of parental awareness as a reason for not immunizing their children. By increasing the awareness and education of parents regarding immunization, the proportion of immunized children increased from 74\%-94\%. Further, motivation, utilization of primary health centers, the immunization status slightly increased from 19 to 22\%; parental knowledge also increases immunization status from 12 to $16.5 \%[11,15]$ Although media campaigns also have shown to improve the coverage especially in the NIDs but remains unsatisfactory.[16]

A study done at Hyderabad, the second big city of Sindh province after Karachi, showed that the commonest reason for not vaccination or incomplete vaccination was a lack of motivation and careless attitude of parents in 56.6\%. Mothers were although aware of its importance but could not find time to take the child to nearby EPI-center or because of the distance of EPI centers in $15 \%$, illness of child in $17 \%$, lack of awareness in $31.29 \%$, no knowledge in $8 \%$ and fear of vaccine in 3.4\% [17] Therefore more health interventions are needed at the hospital and the community level to ensure immunization in children less than five years of age, by improving parental education, motivating them to vaccinate their children which in turn reduce the underfive mortality [18]. So it is clear that quality of immunization services is compromised at the recipient level mainly due to lack of motivation, and doubts about the importance of immunization.

EPIcenter of Civil Hospital Sukkur provides immunization facility to both urban and rural Sindh but one of the surveys done earlier showed hat number of immunized children is still not sufficient and there is also a lack of published data on this issue. Therefore this study was done to determine immunization status and reasons of no-immunization in children so that reasons which are responsible for low or high immunization can be addressed timely thereby reducing morbidity and mortality related to infectious diseases.

\section{Material and Methods}

This cross-sectional analytical study was conducted in the pediatric outpatients department at Civil Hospital Sukkur from January 1, 2013, to June 30, 2013. Parents brought their children under five years of age for any illness were asked to participate in the study. Those parents who gave informed consent were enrolled in the study. Parents refused to participate in this study and those did have vaccination card or missed dose were excluded. Demographic features like the age of the child, the age of mother, the age of father, education of both father and mother socioeconomic status and immunization status. Children were categorized as fully vaccinated if they had one dose of BCG, three doses of hepatitis B, OPV and DPT and one dose of Measles vaccine as recommended by WHO confirmed by vaccination card. Children who did not receive were labeled as unvaccinated. 1) busy parents were defined as parents aware of the importance of vaccination but don't have time to vaccinate, 2) ill child are those who have a cold, cough, fever on scheduled date of immunization, 3) parents consider immunization not important, 4) parents don't have knowledge about immunization and 5) fear of vaccination, if parents afraid of injection and its adverse effects on their children).

The sample size was calculated assuming of vaccination coverage of $70 \%$, bond on the error of estimation of $4 \%$ and confidence level of $95 \%$. The sample size was 500 . The sample size was calculated using WHO software for sample size determination in health studies. The data was entered and analyzed in Statistical Package for Social Sciences (SPSS20) software. Frequency and percentage were computed for categorical and mean and standard deviation were estimated for quantitative variables. The socioeconomic variable is derived using principal component analysis. Logistic regression was applied to ascertain factors of non-vaccination. Variables which were significant at a univariable level were included in the multivariable model. Final model also adjusted for age and sex of the child. Odds ratio with 95\% conference interval were reported. The final model was checked for the goodness of fit using Hosmer \& Lemeshow test.

This study was approved by ethical review committee of the institute. Primary author obtained permission from the principal investigator to write this manuscript.

\section{Results}

Overall 2540 of patients visiting the OPD during the study period of them 613 children under five years of age were visited OPD for any illness. A total of 500 parents gave consent to participate in this study (Figure 1). The mean age of children was $20.5 \pm 16.2$ months, 257 (51.4\%) were male and 243 (48.6\%) were female. The mean age of the father was $42.2 \pm 8$ and mean age of mothers was $32.6 \pm 10.1$ years. One hundred and forty-five (29\%) fathers and 163 (32.6\%) mothers were uneducated, 123 $(24.6 \%)$ belonged to low socioeconomic status and $312(62.4 \%)$ belonged to middle socioeconomic status. Ninety-eight (19.6\%) children were unvaccinated and $402(80.4 \%)$ of children were fully vaccinated. A total of 208 (41.6\%) fathers don't want to

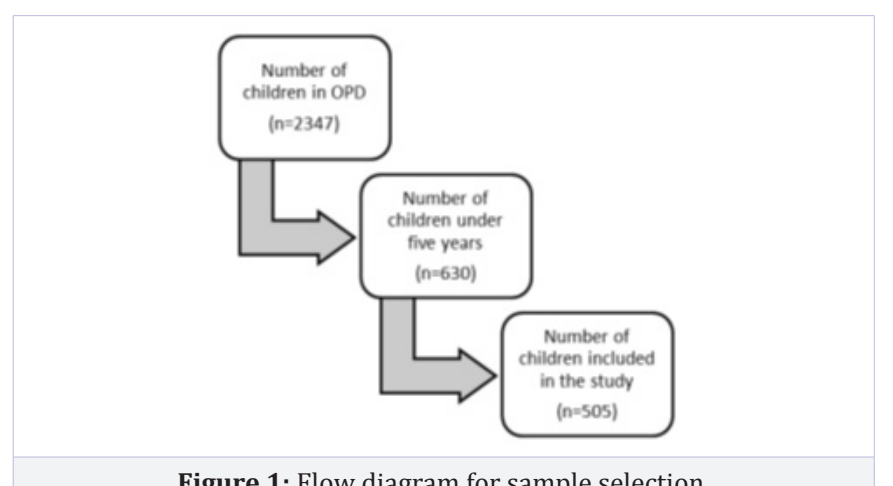

Figure 1: Flow diagram for sample selection. 
immunize, 217 (43.4\%) has ill children, 80 (16\%) busy parents, $72(14.4 \%)$ parents had a fear of vaccination and $72(14.4 \%)$ parents don't think vaccination is important.

The mean age of unvaccinated children was $17.2 \pm 16$ months. Among unvaccinated children, (39.8\%) were male and 59 (60.2\%) were female, $76(77.6 \%)$ belonged to poor socioeconomic strata, $73(74.5 \%)$ fathers and $59(60.2 \%)$ mothers were uneducated Table 1.

Univariable analysis showed age, gender, socioeconomic status, education of father \& mother, busy parents, parents don't know about immunization, the parent having fear and parent considering vaccination as unimportant were significant Table 2.

Multivariable analysis showed high socioeconomic status OR 0.16 (95\% CI 0.09-0.28), education of mother OR 0.34 (95\% CI 0.23-0.49), parents don't know about immunization OR 2.11 (95\% CI 1.02-4.34), busy parents OR 2.6 (95\% CI 1.33-4.98), illness of child OR 3.02 (95\% CI 1.36-6.68), fear of immunization OR 2.53 (95\% CI 1.12-5.34) and parents who are not considering immunization as important OR 3.86 (95\% CI 1.95-7.67) are independent factors of non-vaccination.

Table 1: Comparison of demographic characteristics and factors between vaccinated and unvaccinated children.

\begin{tabular}{|c|c|c|c|c|}
\hline & $\begin{array}{l}\text { Vaccinated } \\
\text { Children } \\
(\mathrm{n}=402)\end{array}$ & $\begin{array}{c}\text { Unvaccinated } \\
\text { Children } \\
(\mathrm{n}=98)\end{array}$ & $\begin{array}{l}\text { Crude } \\
\text { Odds } \\
\text { ratio }\end{array}$ & $95 \% \mathrm{CI}$ \\
\hline Age of children & $21.26 \pm 16.24$ & $17.23 \pm 16.16$ & 0.98 & 0.97-0.99 \\
\hline Female & $184(45.8 \%)$ & $59(60.2 \%)$ & 1 & \\
\hline Male & $218(54.2 \%)$ & $39(39.8 \%)$ & 0.56 & $0.35-0.87$ \\
\hline Age of father & $41.37 \pm 7.88$ & $41.39 \pm 8.41$ & 0.98 & 0.96-1.01 \\
\hline Age of mother & $32.94 \pm 10.24$ & $31.43 \pm 9.86$ & 0.98 & $0.95-1.02$ \\
\hline \multicolumn{5}{|l|}{ Education of father } \\
\hline Uneducated & $72(17.9 \%)$ & $73(74.5 \%)$ & 1 & \\
\hline Educated & $330(82.1 \%)$ & $25(25.5 \%)$ & 0.49 & $0.33-0.56$ \\
\hline \multicolumn{5}{|l|}{ Education of mother } \\
\hline Uneducated & $74(18.4 \%)$ & 89 (90\%) & 1 & \\
\hline Educated & $328(81.6 \%)$ & $9(9.2 \%)$ & 0.27 & $0.19-0.38$ \\
\hline \multicolumn{5}{|l|}{ Socioeconomic status } \\
\hline Poor & 47 (11.7\%) & $76(77.6 \%)$ & 1 & \\
\hline Middle and high & $355(88.3 \%)$ & $22(22.5 \%)$ & 0.27 & $0.19-0.35$ \\
\hline \multicolumn{5}{|l|}{$\begin{array}{l}\text { Factors of non- } \\
\text { vaccination }\end{array}$} \\
\hline $\begin{array}{l}\text { Parents don't want to } \\
\text { immunize }\end{array}$ & $134(33.3 \%)$ & $74(75.5 \%)$ & 6.16 & $\begin{array}{l}3.72- \\
10.22\end{array}$ \\
\hline Illness of child & $141(35.1 \%)$ & $76(77.6 \%)$ & 6.39 & $\begin{array}{l}3.81- \\
10.72\end{array}$ \\
\hline Busy parents & $44(10.9 \%)$ & $36(36.7 \%)$ & 4.72 & $2.82-7.92$ \\
\hline Fear of vaccination & $43(10.7 \%)$ & $28(28.6 \%)$ & 3.25 & $1.89-5.58$ \\
\hline $\begin{array}{l}\text { Parents thinks } \\
\text { vaccination is not } \\
\text { important }\end{array}$ & $78(19.4 \%)$ & $53(54.1 \%)$ & 4.89 & $3.06-7.81$ \\
\hline
\end{tabular}

Table 2: Multivariable model of factors determining non-vaccination in children

\begin{tabular}{|c|c|c|}
\hline Age of children & $\begin{array}{c}\text { *Adjusted Odds } \\
\text { ratio }\end{array}$ & $95 \%$ CI \\
\hline Female & 1.0 & $0.98-1.02$ \\
\hline Educated mother & 1.05 & $0.58-1.93$ \\
\hline $\begin{array}{c}\text { Middle and high socioeconomic } \\
\text { status }\end{array}$ & 0.34 & $0.23-0.49$ \\
\hline $\begin{array}{c}\text { Parents don't want to } \\
\text { immunize }\end{array}$ & 2.11 & $0.09-0.28$ \\
\hline Illness of child & 3.02 & $1.03-4.34$ \\
\hline Busy parents & 2.55 & $1.36-6.68$ \\
\hline Fear of vaccination & 2.53 & $1.19-5.34$ \\
\hline $\begin{array}{c}\text { Parents thinks vaccination is } \\
\text { not important }\end{array}$ & 3.86 & $1.94-7.67$ \\
\hline *Adjusted for age and sex of children & \\
\hline \multicolumn{2}{|c|}{} \\
\hline
\end{tabular}

\section{Discussion}

Immunization is the most cost-effective health strategy for child health. There is an imminent risk of an epidemic of vaccine-preventable diseases due to increasing urbanization, migration, growing slums, highly concentrated population and continuous invasion of new pathogens and low coverage of primary immunization. Attempts to improve the coverage have been going on for many years. The morbidity and mortality due to vaccine preventable disease are still very high in many developing countries including Pakistan. The top five killers in children less than five years include perinatal conditions $20 \%$, respiratory tract infections $18 \%$, diarrheal illnesses $17 \%$, vaccine preventable infections $15 \%$ and malaria $7 \%$ [2].

The results of this study showed that $80.4 \%$ children were fully immunized, and only $19.6 \%$ were not immunized. A low coverage of immunization was observed in the study by Mathew et al. [19] who found that $25 \%$ of children were fully immunized and Saxena et al. [20] found that $30 \%$ were completely immunized. $50 \%$ to $70 \%$ coverage of immunization was observed in different international studies. [21-26] Results of this study indicate a similar immunization status compared to the Indian average according to the NFHS 3 (2005-2006) which showed that $43.8 \%$ of children were fully immunized. [27] In a study in Delhi, the rate of fully vaccinated children was $71.7 \%$, partially vaccinated $19.8 \%$, and unvaccinated $8.5 \%$. [22]

Full immunization was reported in $91 \%$ by parents in Adelaide, [28] 89.7\% in China, [29] and in Islamabad 58\% [30]. Low vaccination coverage in presence of many EPI centers indicates need for education and motivation for both parents and primary health care staff [17].

Coverage of fully immunized children from four states of India, (Bihar, Madhya Pradesh, Rajasthan, and Uttar Pradesh) was reported as $47.8 \%$, and partially and not immunized children as $32.2 \%$ and $20 \%$.[31]

In this study, we found that parents belonged to middle and high socioeconomic status OR 0.16 (95\% CI 0.09-0.28), and 
education of mother OR 0.34 ( $95 \%$ CI $0.23-0.49$ ) were more likely to immunize their children. Studies have shown that education of mother was independently associated with immunization coverage.[33, 34] Study reported that children from urban areas and mother's education level showed significant role in immunization coverage. ${ }^{33}$ By improving female literacy with a reduction in drop-out rate would achieve the higher target of immunization among children.

Risk factors include parents don't know about immunization OR 2.11 (95\% CI 1.02-4.34), busy parents OR 2.6 (95\% CI 1.33-4.98), illness of child OR 3.02 (95\% CI 1.36-6.68), fear of immunization OR 2.53 (95\% CI 1.12-5.34) and parents who are not considering immunization as important OR 3.86 (95\% CI 1.95-7.67) are independent factors of non-vaccination. Similar factors have been identified in a study amongst urban slums of Lucknow district. [23] A study done at Hyderabad, second big city of Sindh showed that the commonest reason for non-vaccination or incomplete vaccination was laziness of parents $(56.6 \%)$. Mothers although aware of its importance could not find time to take the child to nearby EPIcenter or because of the distance of EPI centers in 15\%, due to the illness of child in 17\%, lack of awareness in $31.29 \%$, no knowledge in $8 \%$ and fear of vaccine in $3.4 \%$ [17]. In a study from India the common reasons for partial immunization and non-immunization were: lack of knowledge about vaccination in 30.3\%; side-effects of vaccination in (28.8\%); lack of knowledge about subsequent doses $(22.1 \%)$; lack of faith in the effectiveness of immunization (21.7\%); OPV thought to be the only vaccination in $20.9 \%$; vaccine should not be given if the child is suffering from minor illnesses, such as mild diarrhoea with no dehydration or acute respiratory infections in $12.7 \%$; sickness of the child on the scheduled date in $12.7 \%$; and minor reactions during previous vaccination in $11.9 \%$ [32].

Other factors that are impacting the quality of immunization services are lack of motivation, and prevailing doubts about the importance of immunization. Lack of vehicles, unavailability of local vaccinators particularly for females and misplacement of cards [35] Therefore, solving the problems of the providers at all levels combined with media campaigns to give awareness and modify firm behavior of recipients can meaningfully improve the immunization coverage in Pakistan [35].

This study has certain strengths. The sample size is adequate with $4 \%$ bound on the error of estimation. The socioeconomic variable was derived from principle component analysis. The model was validated by doing sub sampling of data and no difference was found. Logistic analysis was applied to determining factors of non-vaccination.

The study has some limitation. First, we missed partially immunized children but their proportion is low. Second, recall bias and information biases cannot be ruled out. But researcher asked the questions in standard format and probe as needed. This study was done in a busy OPD and parents were in a rush so sample collection took six months.

Vaccine coverage can be enhanced by community-based health education, providing immunization, and follow-up of families, resulting in a decrease in disease burden [36]. There is a need for more clear and appropriate health education messages regarding vaccination of children as well as adequate and quality outreach services of vaccination to counter the cause of busy parents [37].

In conclusion, the immunization status of children visiting the outpatients department of the tertiary-care hospital is low. Only $80.4 \%$ children were fully vaccinated and $19.6 \%$ were non-vaccinated children. The reasons can be multi factorial ranging from low prioritization of immunization by parents, the educational status of mother, busy lifestyle, and unimportance of vaccination due to taboos associated with immunization. These factors should be considered in order to improve planning for improving vaccine coverage.

\section{Acknowledgements}

We are thankful to the staff of pediatric outpatients department for facilitating parents.

\section{References}

1. Ciofi Degli Atti ML, Rota MC, Bella A, Salmons S. Do changes in policy affect vaccine coverage levels? Results of a national study to evaluate childhood vaccination coverage and reasons for missed vaccination in Italy. Vaccine. 2004;22:4351-4357

2. World Health Organization, United Nations Children Fund. The state of the world's children 2015: Reimagine future.

3. Haneef SM, Maqbool S, Arif MA. Textbook of pediatrics. Samanabad, Lahore: immunization; International Book Bank; 2000.

4. World bank Mortality rate, under-5 (per 1,000) 2011-2015. Available online.(accessed on $10^{\text {th }}$ June 2016)

5. National Institute of Population Studies. Pakistan, and IRD/Macro International, Pakistan Demographic and Health Survey, 1990/1991. Islamabad, Pakistan: National Institute of Population Studies; 1992.

6. Pakistan. National Institute of Population Studies (Nips) and IRD/ Macro International. Pakistan Demographic and Health Survey 1990/91. Islamabad, Pakistan, Columbia, Maryland, NIPS, IRD: NIPS; Jul 1992.

7. The government of Pakistan. Multiple indicators cluster survey of Pakistan, 1995. Ministry of Health. Islamabad: Government of Pakistan; 1995.

8. World Health Organization. Training for mid-level managers. Module 7: The EPI coverage survey. Geneva; 2008.

9. Harris JB, Gacic-Dobo M, Eggers R, Brown DW, Sodha SV. Global routine vaccination coverage, 2013. MMWR Morb Mortal Wkly Rep.2014;63(46):1055-1058

10. Peter G. Childhood immunizations. N Engl J Med. 1992;327:17941800. DOI:10.1056/NEJM199212173272507

11. Pakistan Demographic and Health Survey 2012-2013. National Institute of population Studies. 2013; Page 152

12. Eastham KM, Wyllie J. A study of neonatal BCG immunization within an acute hospital trust. J Public Health Med. 2001;23(4):335-338.

13. Ahmed SI, Baig L, Thaver IH, Siddiqui MI, Jeffery SI, Javed A. Knowledge, attitudes and practices of general practitioners in Karachi District Central about Tetanus immunization in adults. J Pak Med Assoc. 2001;51(10):367-369. 
14. Ahmad N, Akhtar T, Roghani MT, Ilyas HM, Ahmed M. Immunization coverage in three districts of North West Frontier Province (NWFP). J Pak Med Assoc. 1999;49(12):301-305.

15. Mansouri FA, Baig LA. Assessment of immunization service in perspective of both the recipients and the providers: a reflection from focus group discussions. J Ayub Med Coll Abbottabad. 2003;15(1):1418.

16. Reichler MR, Aslanian R, Lodhi ZH, Latif I, Khan MA, Chaudhry R, et al. Evaluation of oral poliovirus vaccine delivery during the 1994 national immunization days in Pakistan. J Infect Dis. 1997;175 Suppl 1:S205-209.

17. Sheikh S. Immunization status and reasons for non-vaccination in children attending O.P.D. at Liaquat University Hospital. Pak Paed J. 2003;27:81-86

18. Sheikh S, Mustafa B, Memon GM. One year study of measles and post measles cases admitted in the pediatric ward. Med Channel. 2003;9:14

19. Mathew JL, Babber H, Yadav S. Reasons for non-immunization of children in an urban, low-income group in North India. Trop Doct. 2002;32:135-138.

20. Saxena P, Prakash D, Saxena V, Kansal S. Assessment of routine immunization in an urban slum of Agra district. Indian J Prev Soc Med. 2008;39:60-62.

21. Manjunath U, Pareek RP. Maternal knowledge and perception about the routine immunization program a study in semi-urban area in Rajasthan. Indian J Med Sci. 2003;57:158-163.

22. Khokhar A, Chitkara A, Talwar R, Sachdev TR, Rasania SK. A study of reasons for partial immunization and non-immunization among children aged 12-23 months from an urban community of Delhi. Indian J Prev Soc Med. 2005;36(3-4):83-86.

23. Nath B, Singh JV, Awasthi S, Bhushan V, Kumar V, Singh SK. A study on determinants of immunization coverage among 12-23 months old children in urban slums of Lucknow district, India. Indian J Med Sci. 2007;61(11):598-606.

24. Kar M, Reddaiah VP, Kant S. Primary immunization status of children in slums areas of South Delhi: the challenge of reaching urban poor. Indian J Commun Med. 2001;26(3):151-154.

25. Singh P, Yadav RJ. Immunization status of children of India. Indian Pediatr. 2000;37:1194-1199.
26. Yadav RJ, Singh P. Immunization status of children and mothers in the state of Madhya Pradesh. Indian J Commun Med. 2004;29(3):147-148.

27. International Institute for Population Sciences. National family health survey-3 (2005-06). Mumbai: International Institute for Population Sciences, 2007.

28. Deady J, Thornton L. Parents' knowledge of and attitude towards the primary childhood immunizations. Ir Med J. 2005;98(1):7-8.

29. Guo WS, Zhang YY, Kang K, Diao LQ, Feng DX, Zhao S. Study on the authenticity of parents memory on their children's immunization status. Zhonghua Liu Xing Bing Xue Za Zhi. 2004;25:229-31.

30. Adil MM, Zubair M, Alam AY, Khan SM, Ishtiaque Z, Qureshi AA. Knowledge of mothers about children's immunization status in the urban areas of Islamabad. Rawal Med J. 2009;34(1):33-35.

31. Singh P, Yadav RJ. Immunization status of Children in BIMARU states. Indian J Pediatr. 2001;68(6):495-469.

32. Kumar D, Aggarwal A and Gomber S. Immunization Status of Children Admitted to a Tertiary-care Hospital of North India: Reasons for Partial Immunization or Non-immunization. J Health Popul Nutr. 2010;28(3):300-304.

33. Phukan RK, Barman MP, Mahanta J. Factors associated with immunization coverage of children in Assam, India: over the first year of life. J Trop Pediatr. 2008;55(4):249-52. doi:10.1093/tropej/ fmn025.

34. Mohan P. Inequities in coverage of preventive child health interventions: the rural drinking water supply program and the universal immunization program in Rajasthan, India. Am J Public Health. 2005;95(2):241-244.

35. Mansouri FA, Baig LA. Assessment of immunization service in perspective of both the recipients and the providers: A reflection from focus group discussions. J Ayub Med Coll. 2003;15(1):14-18

36. Tarin E, Khalil M, Mustafa T, Alvi ZM, Sy FS, Thompson SJ, et al. Impact of Community-Based Intervention on Immunization Coverage Against Vaccine-Preventable diseases in Pakistan. Pak J Health. 1999;36:5356.

37. Sultana A, Jahan S, Ahmad I. Knowledge, Attitude and Practice of Immunization in an Urban Population. Pak Armed Forces Med J. 2001;51:177-181. 